\title{
Does Corporate Tax Burden Affect Growth? Evidences from OECD Countries
}

\author{
Bogdan DIMA ${ }^{1}$, Ştefana Maria DIMA²
}

DOI 10.1515/JHEEC-2017-0004

\begin{abstract}
This paper explores the tax burden - economic growth nexus. It advances an explanatory framework for the existence of such nexus. First, we argue that tax burden reduces the income remaining at the disposal of the private sector. Second, we empirically test for the existence of a non-linear impact of corporate tax burden on growth for a dataset of 21 OECD countries, for the period 1975 - 2012. We mostly involve mixed effects models with three levels of nested random effects. Our main empirical result consists in the evidences of a non-linear relation between corporate tax burden and economic growth.
\end{abstract}

Keywords:

Tax burden, growth, mixed effects models, OECD, private sector

JEL Classification: H21, H3O, O4O.

\section{Introduction}

Somewhere in Europe, instead of a highway connecting cultures and communities, there is just a lonely piece of road coming from nowhere and going to nowhere... Bad public management, bureaucracy and corruption led to the waist of allocated resources. Ironically, a banner placed by a public authority tells the few peoples passing by: "Dear citizens! Here are your tax contributions". This is not only a genuine situation, but also a metaphor for the critical importance of the efficient use of public revenues.

\footnotetext{
1 Finance Department, Faculty of Economics and Business Administration, West University of Timisoara, $16 \mathrm{H}$. Pestalozzi St., 300115, Timişoara, Romania, bogdan.dima@e-uvt.ro

${ }^{2}$ Corresponding Author, ECREB - East European Center for Research in Economics and Business, Faculty of Economics and Business Administration, West University of Timisoara, J.H. Pestalozzi Street, No. 16, 300115, Timişoara, Romania, +40.256.592.588, stefana.dima@e-uvt.ro
} 
The recent financial instability period - with its deep roots in the architecture of the international financial system's disequilibria and its profound consequences on the world economy - has revived the interest for the topic of fiscal policy's capacity to sustain growth and to initiate counter-cycle effects. In the last years, several countries have implemented several steps aiming to reformulate their fiscal systems as more "growth-supporting".

A large body of literature deals with the potential distortionary effects of taxation on economic growth in the framework of endogenous growth models (Barro 1990; Barro and Redlick 2011; Milesi-Ferretti and Roubini 1998a, 1998b; Mendoza et al. 1997; Capolupo 2000; Bleaney et al. 2001; Xing 2011; Gemmell et al. 2013). Still, the conclusions derived out of these contributions are far for being non-controversial. Uhlig and Yanagawa (1996) challenge the conventional wisdom, according to which capital income taxes should be low, and show that, under rather mild conditions, higher capital income taxes lead to faster growth in an overlapping generations' economy with endogenous growth.

Several studies empirically asses these conclusions. For instance, Gordon and Lee (2005) find that statutory corporate tax rates are significantly and negatively correlated with cross-sectional differences in average economic growth rates. Arnold (2008) examines the relationship between tax structures and economic growth for 21 OECD countries in a framework that accounts for the accumulation of both physical and human capital. It proposes a ranking of tax instruments with respect to their relationship to economic growth. In this ranking, corporate income taxes seem to exercise the most negative effect on GDP per capita. Still, Xing (2011) provides no robust evidence for favouring, in a growth-oriented perspective, the personal income taxes over corporate income taxes; or for favouring consumption taxes over income taxes. The only robust result is that shifts in tax revenue towards property taxes are associated with a higher level of income per capita on the long run.

Acosta-Ormaechea and Yoo (2012) investigate the relationship between changes in tax composition and long-run economic growth, for 69 developed and developing countries, between 1970 and 2009. They conclude that increasing income taxes, while reducing consumption and property taxes, is associated with slower growth on the long run.

Arnold et al. (2011, F76) find that: "In some cases, such as the reduction of corporate taxes and the top rate of personal income tax, it is unlikely that these growth-enhancing changes will help the recovery from the current crisis".

However, as Bergh and Henrekson (2011) note, on the relationship between the size of government and economic growth, in the related literature, there are some contradictory findings for the empirical assessment of tax burden - growth linkage. These can be explained by the differences in the adopted definitions of tax burden, as well as by the specific features of the considered countries.

We seek to contribute to this literature in several ways. First, we advance an explanatory framework for the interactions between taxation and growth. Instead of focusing on a specific growth model, we consider the potential impact of taxation on growth, as induced via the social utility function. On one hand, we argue that tax burden reduces the income remaining at the disposal of the private sector. Hence, there is an eviction effect between 
public and private income. On other hand, the fiscal revenues collected by public authorities support the provision of growth-supporting public goods. If these goods are growth-supporting, then a positive effect on growth emerges. However, there is a threshold level of the tax burden. Above it, any potential supporting effect of taxation is exhausted and this will start inhibiting growth. We mainly consider the case of corporate tax burden as this is inducing micro-economic effects on business environment and is influencing the investment and saving decisions in the long-run.

Second, we empirically test for the existence of a non-linear impact of corporate tax burden on growth for a dataset of 21 OECD countries, for a time span between 1975 and 2012. We mostly involve mixed effects models with three levels of nested random effects. In the quantile regression approach, some differences between the considered countries are highlighted.

Our main theoretical result states that, under some conditions, taxation might stimulate economic growth, at least to a certain critical point. Beyond this point, the tax burden will detrimentally impact growth. At empirical level, we find that evidences of a non-linear relation between corporate tax burden and economic growth. The net effect for OECD countries is a positive, although relatively small one. However, the robustness of the tax burden-growth linkage may vary according to the overall development level, as well as to the existence of some regime-shift periods for growth.

Third, based on our findings, we mention several policy implications.

The remainder of the paper is structured as follows. Section 2 describes the conceptual framework. It conveys the tax burden and growth linkage via a social utility function, which considers as main determinants of social utility: the net income at the disposal of the private sector, the supply of public goods as well as the synergic interactions between growth and public expenditures. Section 3 refers to the involved methodology, while Section 4 describes the OECD dataset. Section 5 reports the results. Section 6 assesses the robustness of the findings. Section 7 concludes.

\section{The conceptual framework: tax burden and economic}

\section{growth}

We advance a novel model aiming to link taxation and economic growth, as established via the impact exercised by the tax burden on social utility. Such model depicts the aggregate social utility as being influenced by economic growth and the supply of public goods and services. Hence, we consider the following social utility function of the private sector (households and private companies) for a given period $t$ in a country $i$ :

$U^{i}{ }_{t}=\alpha_{0}+\alpha_{1} g_{t}^{i}\left(1-\operatorname{tax}_{t}^{i}\right)-\alpha_{2}\left[g^{i}{ }_{t}\left(1-\operatorname{tax}_{t}^{i}\right)\right]^{2}+\beta_{1} B_{t}^{i}-\beta_{2} B^{i 2}{ }_{t}+\chi g^{i}{ }_{t}\left(1-\operatorname{tax}_{t}^{i}\right) B_{t}^{i}$

Here tax is the level of tax burden (as a fraction of economic output), while gi is the level of overall economic outcome. Hence, the term denotes the "net" outcome during the 
current period t at the disposal of private sector. Also, $B$ reflects the supply of public goods and services.

This model incorporates several features: a non-linear version of the Easterlin paradox, a non-linear influence of public provisional of goods with a global social utility and, respectively, the interactions that can be established between growth and public expenditures.

\subsection{Easterlin Paradox: the Happiness Economics' Argument}

The non-linear term $\left[g^{i}{ }_{t}\left(1-\operatorname{tax}_{t}{ }_{t}\right)\right]^{2}$ is aiming to deal with the Easterlin paradox (Easterlin 1974, 1995; Easterlin et al. 2010) according to which: "over the long-term... happiness does not increase as a country's income rises" (Easterlin et al. 2010, 22463). Even if a substantial stream of literature on this topic can be noticed (a simple search on Google Scholar on "Easterlin paradox" yields more than 7400 results), currently there is no real consensus on this statement (see Veenhoven and Vergunst [2013] for a detailed discussion). Recent available data (such as those from World Database of Happiness) are rather contradicting it. For instance, Sacks et al. (2012) find that well-being rises with income, whether there are involved comparisons: between people in a single country and during one year; across countries; or of economic growth levels for a given country. Their results suggest that absolute income plays a major role in determining well-being. Also, they don't find evidences for a 'satiation point', above which income and well-being are no longer significantly related. Still, our specification for the utility function considers the possible existence of such point. We argue that both absolute and relative income might matter for the social utility and, so, some Easterlin-type effects might occur in a non-linear specification. Our argument maybe resumed as follows: rich countries can overall enjoy higher subjective well-being than poor countries: cumulatively, the absolute level of income exerts a positive and robust impact on subjective well-being. But, individuals from a given country engage themselves in some comparison with other fellow citizens. As Corcoran et al. $(2011,119)$ reason: "Social comparisons - comparisons between the self and others - are a fundamental psychological mechanism influencing people's judgments, experiences, and behavior. People constantly engage in social comparisons". In assessing the degree of satisfaction with their lives, individuals account for a complex set of objective and subjective factors. Among these, the self-perceived social position is an important variable. Consequently, the place occupied by an individual in the social distribution processes (and, thus, its relative income) can influence the subjective evaluation of well-being. The "I'm happy not only if I gain a certain amount of money, but also if I gain more than my neighbour" argument can be viewed as related to the long lasting components of "life as a whole" narrative and (perhaps) less with its short-run transitory components. 
We also argue that a sustainable growth of income may affect the distribution mechanisms: the size of the cake may influence how the cake is split. Thus, one can expect significant differences in the distribution mechanisms between rich and poor countries, as well as changes in these mechanisms during growth processes. One can note that "change" is not always and necessarily equivalent with "improvement": some phases of economic growth might be accompanied by an increase in social disparities and by a higher inequality in income distribution. By improving or worsening the social equilibriums, the growth may alter the characteristic social utility function.

Supplementary, in the age of globalization, the individuals from rich countries possess, at least, some general information about the living conditions in poor countries. Even if such "educated" members of a society represent only a fraction of the total population, they might consider using some referential under such conditions in estimating their life satisfaction. They compare their situation not only with that of their direct neighbours, but also with that of other neighbours from the "global village". Migration, trade, foreign investments and the activity of multinational companies or cultural exchanges can stimulate such comparisons. Finally, at an empirical level, we argue that the Easterlin paradox might be the outcome of a neglected non-linearity in the relationships between involved variables.

Hence, our argument conveys the idea that albeit the absolute income is a significant part of the story, the relative income can also play a certain role in linking income and subjective well-being. Thus, even if there is no satiation point, the income-social utility relation can display a non-linear profile due to the impact of income distribution processes on life satisfaction.

\subsection{Public Goods Supply and Social Utility: the Ricardian Equivalence Theorem' Argument}

The considered non-linear impact of public goods supply on social utility is designed to reflect the possible existence in the economy of some neo-Ricardian agents: if the Ricardian Equivalence Theorem applies to such agents, then a current observed increase in the supply of public goods level will lead, above a certain threshold, to a change in the current consumption and savings in order to meet future possible increases in public debt and taxes and, thus, will affect their current utility.

Furthermore, the supply of public goods and services is related to the capacity of public authorities to mobilize fiscal and non-fiscal financial resources from the economy and to efficiently use them as well as to carry out their politic and social goals. Hence:

$$
B_{t}^{i}=\Omega_{t}\left[b_{1} \operatorname{tax}_{t}^{i}-b_{2}\left(\operatorname{tax}_{t}^{i}\right)^{2}+b_{3} e_{t}\right]
$$


Here $e$ is the income of public authorities from economic activities of the public sector (rescaled with the total economic output), while $\Omega$ is a parameter controlling for the preferences of policy-makers. Even if one considers the post-ideological policy' argument (with its equivalent "rush to the centre" in the design of public policies), this parameter can still be related to the political business cycle and the counter-cycle nature of policies. Broadly, we are not viewing this parameter as being simply "decorative". Rather, we argue that it can be used so as to connect our model with a version of the political business cycle theory applied in this case to the fiscal policy (Nordhaus 1989; Schuknecht 1996; Andrikopoulos et. al. 2004).

The non-linear shape from equation (2) accounts for the possible existence of a Laffer curve effect: if there is a trade-off between tax rates and the total tax revenues actually collected by the public authority, then such trade-off may occur as well between tax rates and the supply of public goods.

The content of $B^{i}$ is not necessarily limited to the traditional set of goods and services. Rather, this variable can be viewed in a broad sense by relating it to the overall quality of public institutions and policies as is this impacted by the fiscal policy. Hence, this model can be fully integrated with the neo-institutionalism view, according to which good governance is a critical pre-request of economic growth (Rauch and Evans 2000; Swank 2002; Knack 2003).

In fact, this is an important part of our argument: public authorities can compensate for a higher level of tax burden, by providing an adequate supply of public goods and by ensuring a higher quality of public policies and transparent, accountable and efficient system of public institutions.

\subsection{Growth and Public Expenditures: the Reciprocal Linkages Argument. Conclusions}

The multiplicative term $g_{t}^{i}\left(1-\operatorname{tax}_{t}^{i}\right) B_{t}^{i}$ of the utility function captures the bi-univocal interactions between growth and the productive government expenditures. On one hand, the supply of some public goods - such as public infrastructure, public expenditures related to human capital (such as education, research or health) or public expenditures in low productivity sectors - as well as sound and efficient public institutions can support growth (see, for instance, Irmen and Kuehnel [2008] for an extended survey of the literature). On the other hand, economic growth mobilizes more resources at the disposal of public authorities. Thus, one migth consider the potential sinergic effect of growth and the supply of public goods and services.

By substituting (2) in (1), the social utility function can be rewritten as:

$$
\begin{aligned}
U^{i}{ }_{t}= & \alpha_{0}+\alpha_{1} g^{i}{ }_{t}\left(1-\operatorname{tax}_{t}^{i}\right)-\alpha_{2}\left[g^{i}{ }_{t}\left(1-\operatorname{tax}_{t}^{i}\right)\right]^{2}+ \\
& \beta_{1} \Omega_{t}\left[b_{1} \operatorname{tax}_{t}^{i}-b_{2}\left(\operatorname{tax}_{t}{ }^{2}\right)^{2}+b_{3} e_{t}\right]-\beta_{2} \Omega^{2}{ }_{t}\left[b_{1} \operatorname{tax}_{t}^{i}-b_{2}\left(\operatorname{tax}_{t}^{i}\right)^{2}+b_{3} e_{t}\right]^{2}+ \\
& \chi g^{i}{ }_{t}\left(1-\operatorname{tax}_{t}^{i}\right) \Omega_{t}\left[b_{1} \operatorname{tax}_{t}^{i}-b_{2}\left(\operatorname{tax}_{t}{ }_{t}\right)^{2}+b_{3} e_{t}\right]
\end{aligned}
$$


The level of the overall economic outcome maximizing social utility, $g^{*}$, can be estimated by imposing the condition: $\frac{\partial U^{i}}{\partial g}=0$. Hence:

$$
\begin{aligned}
& \alpha_{1}\left(1-\operatorname{tax}_{t}^{i}\right)-2 \alpha_{2} g^{*_{i}}{ }_{t}\left(1-\operatorname{tax}_{t}^{i}\right)^{2}+\chi\left(1-\operatorname{tax}_{t}^{i}\right) \Omega_{t}\left[b_{1} \operatorname{tax}_{t}^{i}-b_{2}\left(\operatorname{tax}_{t}^{i}\right)^{2}+b_{3} e_{t}\right]=0 \\
& \Rightarrow g^{*_{i}}{ }_{t}=\frac{1}{2 \alpha_{2}\left(1-\operatorname{tax}_{t}^{i}\right)}\left\{\alpha_{1}+\chi \Omega_{t}\left[b_{1} \operatorname{tax}_{t}^{i}-b_{2}\left(\operatorname{tax}_{t}\right)^{i}+b_{3} e_{t}\right]\right\}
\end{aligned}
$$

The de facto output, $g^{i}$ may deviate (in a non-linear fashion) from its optimal level, $g^{*} i$ under the impact of different shocks located at the level of various exogenous and endogenous factors, $x$. Thus:

$$
g^{i}{ }_{t}=g^{*_{i}}{ }_{t}+d_{1} x_{t}+d_{2} x^{2}{ }_{t}=\frac{1}{2 \alpha_{2}\left(1-\operatorname{tax}_{t}^{i}\right)}\left\{\alpha_{1}+\chi \Omega_{t}\left[b_{1} \operatorname{tax}_{t}{ }_{t}-b_{2}\left(\operatorname{tax}_{t}{ }_{t}\right)^{2}+b_{3} e_{t}\right]\right\}+d_{1} x_{t}+d_{2} x^{2}{ }_{t}
$$

Equation (5) depicts the main argument of the model: the economic output is functionally related in a non-linear manner to taxation. The involved transmission mechanisms are associated with the linkages between economic growth and social utility, the supply of public goods and the policy preferences of policy-makers. In caeteris paribus conditions, any change in tax burden will impact economic output depending on the following key elasticities: the elasticities of social utility in respect to linear and non-linear terms for net outcome; the elasticity of social utility in respect to the term describing the multiplicative interactions between growth and public expenditures; and the elasticities of public good supply in respect to public incomes from taxation and public sector economic activities. A key feature of the model is that an increase in tax rates will not inhibit growth as long as the turning point in Laffer curve does not occur (or, alternatively, $b_{1} \geq b_{2}$ ) (and the preferences of policy-makers are unchanged). The $\frac{b_{1}}{b_{2}}$ ratio accounts for various cases (including those in which a decrease in taxes will not lead to an increase in the income at the disposal of public authorities, but an increase in these will cut off such income - or, in other words, the cases in which the relationship between taxes and the supply of public goods is downside inelastic).

Moreover, this model may be used to study the link between growth and tax composition: tax $_{t}{ }_{t}=\omega^{1}{ }_{\text {taxcorp }}{ }_{t}+\omega^{2}{ }_{\text {taxpers }}{ }^{i}{ }_{t}$ (where: taxcorp are the taxes related to companies, taxpers are the taxes related to households - as a share in the economic output, while $\omega^{1} t$ and $\omega^{2} t$ are their corresponding weights in total taxation):

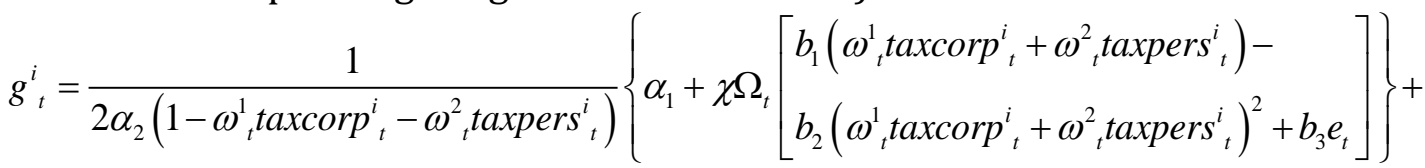

$$
\begin{aligned}
& +d_{1} x_{t}+d_{2} x^{2}{ }_{t}
\end{aligned}
$$

Equation (6) highlights the role played by corporate tax in model's mechanics. For instance, in a steady state $(\dot{x} \rightarrow 0)$ with no income from public sector $\left(e_{t} \rightarrow 0\right)$ and with 
a low weigth of personal taxes in the structure of total taxation $\left(\omega_{t}^{2} \rightarrow 0\right)$, the expression will collapse to:

$$
\begin{aligned}
g_{t}^{i} & \rightarrow \frac{1}{2 \alpha_{2}\left(1-\omega_{t}^{1} \operatorname{taxcorp}_{t}{ }_{t}\right)}\left\{\alpha_{1}+\chi \Omega_{t} \omega_{t}^{1} \operatorname{taxcorp}_{t}^{i}\left[b_{1}-b_{2} \omega_{t}^{1} \text { taxcorp }_{t}{ }_{t}\right]\right\}= \\
& =\frac{1}{2 \alpha_{2}\left(\mu_{t}-1\right)}\left\{\alpha_{1} \mu_{t}+\chi \Omega_{t}\left[b_{1}-b_{2} / \mu_{t}\right]\right\} \text { with } \mu_{t}=\left(\omega_{t}^{1} \text { taxcorp }_{t}{ }_{t}\right)^{-1}
\end{aligned}
$$

Equation (7) resumes our main research hypothesis:

H: In caeteris paribus conditions, there is a non-linear relation between corporate tax burden and income. Such relation is conditioned by the nexus between social utility, the supply of public goods and services and policy-makers preferences.

Several arguments can be formulated in order to support this hypothesis. First, one can argue that an increase in tax burden will force companies to better select their investment projects with higher and less volatile returns. Still, above a certain threshold, an increase in taxes will drain the financial resources at their disposal and will inhibit their capacity to invest. Second, the public authorities can use the collected taxes in order to improve infrastructure, to support research and development expenditures or to improve business environment. Third, taxation can affect the structure of the demand for capital goods by inducing a shift in it, from capital goods with lower marginal productivity to goods with higher marginal productivity and better incorporated technologies. As Auerbach (2005, 3) notes, "expected changes in tax provisions exert their impact through the capital goods inflation rate... When tax provisions change over time, it is the inflation rate of the effective capital goods price... that matters". An anticipated increase in capital goods' prices - as induced, for instance, by an increase in the expected taxes - may spur the current investments. Similar type of effects might be exercised by the anticipated changes in the tax shields and in the depreciation regime. If such anticipated changes exceed a certain level, it will inhibit the current investments, as companies presently need to save in order to meet possible unmatched future flows of expenditure and income. Such adjustments can take place only gradually with the companies' capital adjusting toward the desired level with a certain speed. The current cost of capital will solely influence the current capital demand, only if no future changes in taxation (and in other specific elements) are expected.

One can notice that the proposed model does not imply any specification of the production function. Hence, it is not directly related to the endogenous growth models, such as Barro (1990) type. In a broader sense, it can be viewed as being compatible with this theoretical groundwork, since it focuses on the linkage between social utility - enhancing supply of private production - improving public goods. It implies the existence of various transmission channels for the impact of tax burden on growth, which are mainly related to the sinergic interactions between growth and the supply of public goods. Also, it shares with the endogenous growth models, the idea that the negative effects of higher taxation can be, at least partially, offset by public expenditures (such as those for infrastructure, research, education and health care), leading to higher long term growth. Meanwhile, if the thesis, that the quality of public and semi-public institutions is a significant determinant of growth, is accepted, then the model can be extended in order to account for the neo-institutionalism arguments. 
The existence of the mentioned transmission channels may lead to non-linear links between corporate tax and growth. In the next sections, we search for empirical evidences on OECD countries.

\section{Methodology}

Our baseline empirical model, accounting for cross- and time-specific effects, may be specified as:

$g_{i, t}=\alpha_{1}+\alpha_{2} \operatorname{taxcorp}_{i, t}+\alpha_{2} \operatorname{taxcorp}_{i, t}^{2}+\beta_{1} x_{i, t}+\beta_{2} x_{i, t}^{2}+v_{i}+\gamma_{t}+\varepsilon_{i, t}, i=1, \ldots, N t=1, \ldots, T$

Here $g_{i, t}$ is a measure of economic growth, taxcorp denotes once again the taxes related to companies, $x_{i, t}$ is the matrix of the control variables (supposed to exercise a non-linear impact on growth), $v_{i}$ are the panel-level effects (which may be correlated with the covariates), while $\gamma_{t}$ are time effects, and $\varepsilon_{i, t}$ are i.i.d. shocks. $v_{i}$ and $\varepsilon_{i, t}$ are assumed to be independent for each $i$ over all $t$.

We consider several estimation methods. First, we consider the Prais-Winsten transformed regression estimator, correcting for first-order serially correlated residuals. Such autocorrelations in residuals might appear as a consequence of the hysteresis features of economic growth processes. The model is a generalized least-squares (GLS) estimator and is derived from a $A R(1)$ model (see Becketti [2013]).

Second, we fit a generalized linear model (GLM) (see Hardin and Hilbe [2012]). This class of models is a flexible generalization of ordinary linear regression. It allows for response variables that have error distribution models, other than a normal distribution describing $g_{i, t}$ with covariates $x_{i, t}$ as: $h\left\{E\left(g_{i, t}\right)\right\}=\beta x_{i, t}, g \sim F$ with parameters $\Theta_{i, t} h()$ is called the link function, and $F$ is the distributional family. In our specification, we consider that the distribution of the dependent variable is gamma type, as a two-parameter family of continuous probability distributions.

Our main specifications involve mixed effects models. These models contain both fixed and random effects (that can take the form of either random intercepts or random coefficients). They provide robust estimates of treatment and other fixed effects, when correlated errors derive from a data hierarchy (see for a detailed presentation of such models: Andrews et al. [2006]; Raudenbush and Bryk [2002]; Rabe-Hesketh and Skrondal [2006, 2012]; Schunck [2013]).

Initially, we consider a linear mixed effects model. In matrix notations, such model takes the form:

$$
g=\beta X+u Z+\varepsilon
$$

Here $X$ is the design / covariate matrix for the fixed effects $\beta$ and $Z$ is the design/covariate matrix for the random effects $u$. The effects $\varepsilon$ are assumed to be multivariate normal with zero mean and variance matrix $\sigma_{\varepsilon}^{2} R$. The fixed component, $\beta X$, is the same as the linear predictor from a standard OLS regression, while for the random component $u Z+\varepsilon$ it is asummed to display a variance-covariance matrix $\mathrm{G}$ and that $\mathrm{u}$ is orthogonal to $\varepsilon$ : 


$$
\operatorname{Var}\left[\begin{array}{l}
u \\
\varepsilon
\end{array}\right]=\left[\begin{array}{ll}
G & 0 \\
0 & \sigma_{\varepsilon}^{2} R
\end{array}\right]
$$

Furthermore, we fit mixed-effects generalized linear models allowing various distributions for the conditional response on normally distributed random effects (see McCulloch et al. [2008]; Ng et. al. [2006]). We consider the gamma distribution for the dependent variable together with a log type link function.

For both types of models, we consider a three levels' specification with nested random effects (the random effects shared within lower-level subgroups are unique to the upperlevel groups). Each country is nested into a region and regions are nested into a religious denomination group. Hence, our specification will include now two random-effects equations: the first is a random intercept (constant only) at the religious denomination level (level three); the second is a random intercept at the region level (level two). We argue that countries from the same geographical region are likely to experiment some common shocks and / or business cycle synchronization, especially if they are displaying similar levels of economic growth. Also, based on arguments and evidences from Barro and McCleary (2003) and McCleary and Barro (2006), we consider the interactions between growth and religious denomination. Such Weberian theme implies that a particular formulation of religion dogmatic content may stimulate growth by sustaining aspects of individual behaviour, which enhance work attitudes and productivity.

We expect this specification to capture some of the effects of random shocks' nested levels that might affect growth and, so, to provide a more realistic description of the associated transmission channels.

One issue related to the involved specifications may concern the reverse causality problems. There is not only a direct causality running from taxation to growth, but also an indirect one, from the current economic conjuncture to the capacity of public authorities to collect taxes. In order to assess the robustness of our results, in respect to this potential bi-univocal connection between taxation and growth, we consider a System Generalized Method of Moments (GMM) estimator based on Arellano-Bover/Blundell-Bond framework (Arellano and Bover 1995; Arellano and Bond, 1991, 1998; Blundell and Bond 1998). Still, the System GMM can be affected, as well, by the proliferation of the used instruments: "The difference and system GMM estimators ... can generate moment conditions prolifically, with the instrument count quadratic in the time dimension of the panel, $T$. This can cause several problems in finite samples...A finite sample may lack adequate information to estimate such a large matrix well...A large instrument collection can overfit endogenous variables" (Roodman 2009a, 98-99). Moreover, too many instruments might weaken the Hansen test of over-identifying restrictions (even if they are individually valid) (Roodman 2009b).

For obtaining the estimates, we use the xtabond2 Stata module developed by Roodman (2009a). This provides a great amount of flexibility in the specification and, equally important, allows collapsing the instruments to alleviate the mentioned issues.

Finally, one can argue that the impact of changes in taxation on growth may vary under the impact of various institutional, social and cultural factors between groups of countries even if they are characterized by a high degree of similarity in the global economic status. Hence, when addressing the link between corporate tax burden and growth, a different behaviour of the various sub-groups maybe expected. This behaviour can be mirrored by 
the quantile regression approach. The approach provides several advantages, such as generating robust estimates, particularly for the misspecification errors related to heteroskedasticity, non-normality and other error term misspecification. Additionally, it allows dealing with the error measurement problems. Since Koenker and Bassett (1978) and Bassett and Koenker (1978), an extensive literature has studied the asymptotic behaviour of the quantile regression (see, for instance, Weiss [1990]; Portnoy [1991]; Knight [2008]).

\section{OECD data}

The dataset covers a time span between 1975 and 2012 for 21 OECD member countries (Australia, Austria, Belgium, Canada, Denmark, Finland, France, Germany, Greece, Ireland, Italy, Japan, Korea, Netherlands, New Zealand, Norway, Spain, Sweden, Switzerland, United Kingdom, and United States). The data are collected from OECD statistic database (http://stats.oecd.org/).

The dependent variable for economic growth is the corresponding level of GDP per head (logarithm) (US \$, constant prices, constant PPPs, reference year 2005). In order to attenuate the impact of short-run shocks related to current business cycles, we consider five-year averages of this variable. This way to estimate growth might contribute as well to partially mitigate the problems related to the potential reverse causality. There are 38 observations for each individual country (798 panel observations).

The main explanatory variable is corporate tax burden which is a proxy of public revenues (as \% of GDP) from taxes on companies' profits and taxes on their capital gains.

Based on the literature addressing economic growth, we consider several control variables: inflation volatility, the degree of openness, the labour costs and the abundance of natural resources. Judson and Orphanides (1999) find that that inflation volatility is robustly negatively correlated with growth, even after the effect of the inflation level is controlled for. Also, a strong positive relationship between openness and growth is expected (Yanikkaya 2003; Andersen and Babula 2008; Freund and Bolaky 2008). As we argue that, for developed countries, a substantial fraction of upward trends in labour cost is related to the cost of improvements in human capital and labour force skills and knowledge, we include the total labour costs as explanatory. For instance, OECD (2012, 182 ) estimates that: "Over the past decade, more than half of the GDP growth in OECD countries is related to labour income growth among tertiary-educated individuals". Finally, as Stijns (2005) shows natural resources may affect economic growth, both positively and negatively. Hence, we consider a potential non-linear connection between the abundance of resources (as this is proxy by the contribution of natural resources to GDP) and economic growth.

Some criticisms might be raised in respect to these variables. In our view, one of the most serious is formulated by Gemmell et al. $(2013,14)$ : "since taxes are hypothesised to impact on output partly via physical and/ or human capital investment, arguably these controls will capture some of fiscal effects of interest, leaving only productivity-transmitted effects 
to be picked up by tax rates variables". However, we argue that our approach is not restricted to the supply-side. Rather, we consider a full spectrum of potential effects induced by tax burden via the social preferences and the supply of public utilities, since these are considered determinants of social utility function. Thus, the mentioned controls might explain their impact on growth via channels that are autonomous in respect to those related to the impact of tax burden. Also: "theoretical arguments would lead us to expect different responses to marginal versus average rates...firms' investment location decisions will be more influenced by the effective average rate of corporate tax on investment. The effective marginal rate is, however, likely more relevant to subsequent investment choices, conditional on location, while choices over the location of profit across tax jurisdictions are more influenced by the statutory corporate rate" (Gemmell et al. 2013, 11). Indeed, the average versus marginal effect is expected to be different in terms of the involved transmission channels and reactions' elasticities. Still, our point is that what matters is not only the taxonomy of tax rates per se, but also (and perhaps equally important) the capacity of public authorities to collect (and efficiently use) various types of fiscal revenues given the tax evasion or different opportunistic behaviours of tax payers. Such capacity is more directly reflected by tax burden than by marginal or statutory levels.

Similar to the dependent variable, all the explanatory variables are computed as five-year averages. To facilitate the analysis, these variables $X$ are rescaled in order to display a zero mean and unit variance:

$$
X_{i}^{\text {rescaled }}=\frac{X_{i}-\bar{X}}{\sigma^{2}(X)}
$$

Supplementary, we control for the initial levels of economic growth the levels corresponding to GDP per capita averages between 1970 and 1974).

Our analysis time span covers a period rich in major economic events that might be seen as sources of regime-shifts at data level. Among these: the early 1980s recession with high unemployment affecting OECD countries until 1985; the 1986 to 1991 economic bubble in Japan; the Finish and Swedish banking crisis at the beginning of 1990s; the 1997-1998 Asian financial crisis; the early 2000s recession; the subprime mortgage crisis and its impact leading to the Great Recession of 2007-2012 (see, for a survey on the current literature on economic and financial crisis, Lo [2012]). The values of the skewness (0.144) and kurtosis (1.662) parameters for GDP data highlight important deviations from the normal distribution and fat-tails effects in the data. Hence, the chosen estimation methodologies should account for the potential existence of several structural breaks in data.

However, as Bergh and Henrekson (2011) note, OECD countries are not just a random sample of rich countries. Instead, they are displaying similar structural, functional and institutional characteristics, unified by the prevalence of market mechanisms, commitment to democracy and high living standards. So, even in the presence of such 
breaks, the results might be (at least, at a certain degree) less affected by the problems usually associated with data heterogeneity.

Figure 1 displays the evolution of corporate tax and economic growth for OECD countries. At the level of these countries, our measure of corporate tax burden, as a share of GDP, fluctuates between $2.16 \%$ in 1975 and $2.10 \%$ in 1985 . In the next 30 years it slowly increases reaching a maximum of $3.53 \%$ in 2005 . The Great Recession led to a reduction in economic output and in revenues collected from taxation.

Figure 1. Corporate tax revenue and real GDP per head over time

5-year average of corporate taxes revenue (\% GDP) 21 OECD countries; 1975-2012

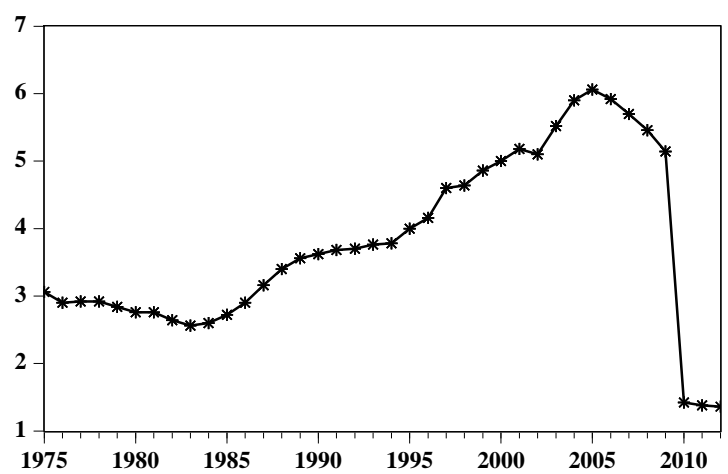

5-year average of real GDP perhead $(\log )$; 21 OECD countries; 1975-2012

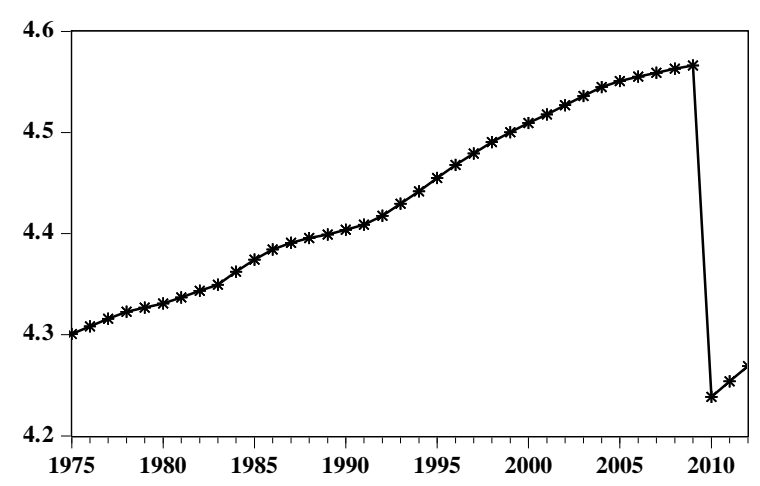

\section{$\rightarrow$ Mean}

The dataset includes cases of countries with relatively low levels of corporate tax burden, such as Greece (less than 1\% of GDP from 1975 to 1989), Spain (with corporate tax burden less than $1.5 \%$ of GDP in the beginning of 1980s), Denmark with a corporate tax burden lower than 1.5\% of GDP between 1975 and 1984, or Korea with comparable levels for the time span. Also, it includes cases of higher tax burden, such as Nordic countries (Norway with revenues from corporate tax of more of $10 \%$ in the beginning of 2000s; and Sweden with a share of more than $4 \%$ of GDP for the entire analysis period) or Japan (with around $6 \%$ of GDP in the 1990s).

Such evolutions of corporate tax burden had been accompanied by an increase with almost $10 \%$ of the corporate tax rate from 1970 to 1980, while the subsequent 30-year period is characterized by a tendency of decline in this rate (Dackehag and Hansson 2012). Meanwhile, there was a relatively stable path for economic growth for OECD countries (with a severe drop in the context of financial and economic recent turmoil).

The kernel (Epanechnikov) fit from Figure 2 suggests a non-linear relationship between growth and companies' taxation as predicted by the proposed model. However, a more detailed analysis of such relation is required. 
Figure 2. Kernel (Epanechnikov) fit for income and social tolerance indicator (rescaled values; full sample, 1975-2012)

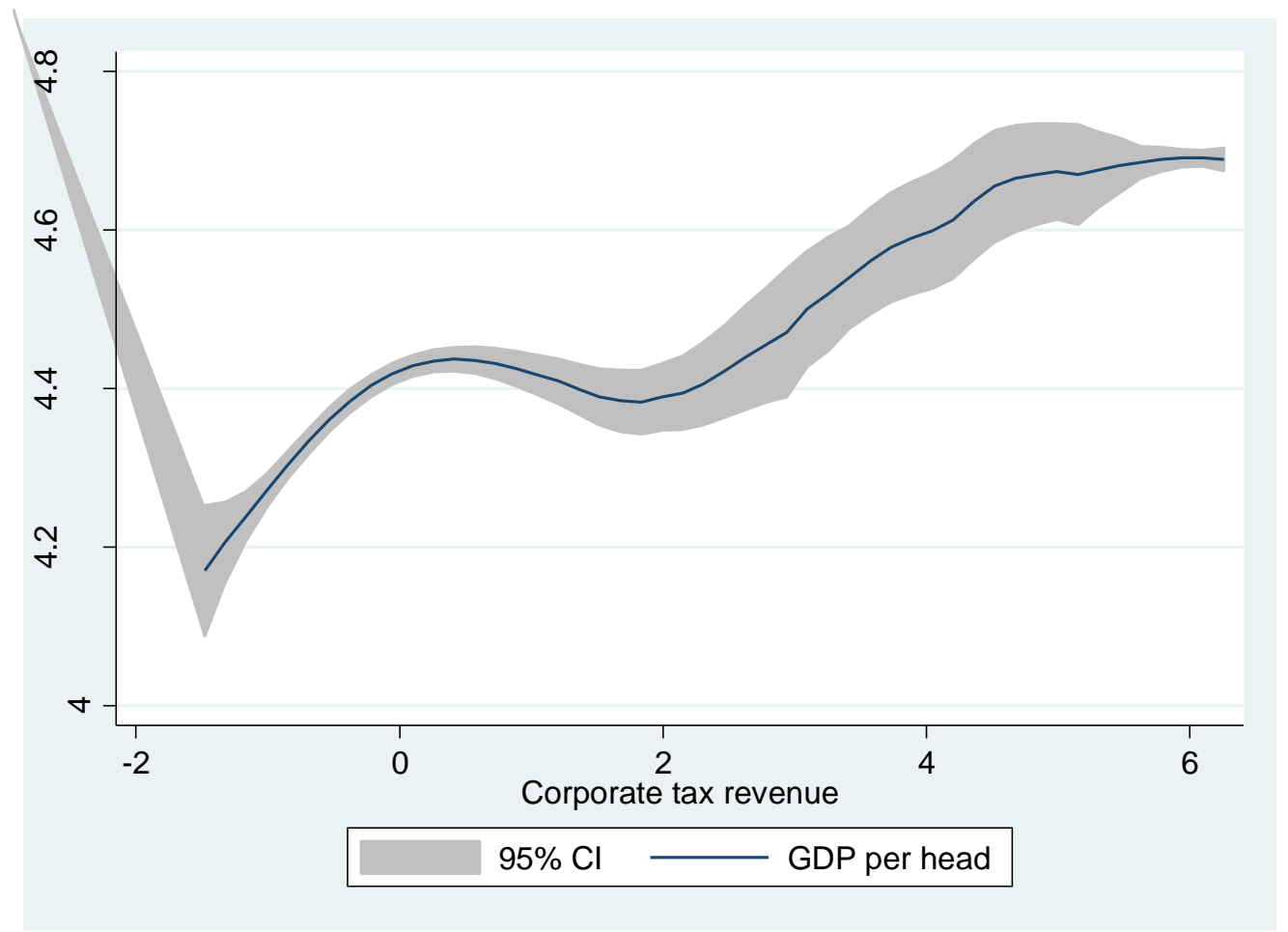

5. Results and comments

\subsection{Prais-Winsten and GLM estimators}

As an initial step, in Column 1 of Table 1 we include only the corporate tax burden level and squared terms in fixed-effects estimation. Both terms are statistically significant at $1 \%$; the level term is positive, while the squared term is negative (although the level of this term is almost seven times lower).

We further continue our preliminary analysis with Prais-Winsten estimators and, respectively, GLM estimators. The results are reported in Column 2 and Column 3 of Table 1.

The levels of corporate tax burden had a positive and for both estimation methods statistically significant at $1 \%$ impact on economic growth, while the squared term has a negative and significant at $1 \%$ impact on growth. There is an inverted $U$-shape effect of corporate tax burden on growth: an increase in the former tends to stimulate growth up to a critical threshold. Above such threshold, the tax burden will start inhibiting growth. As negative impact's amplitude is substantially lower in both specifications, it seems that the net effect of corporate taxes for OECD countries is positive. 


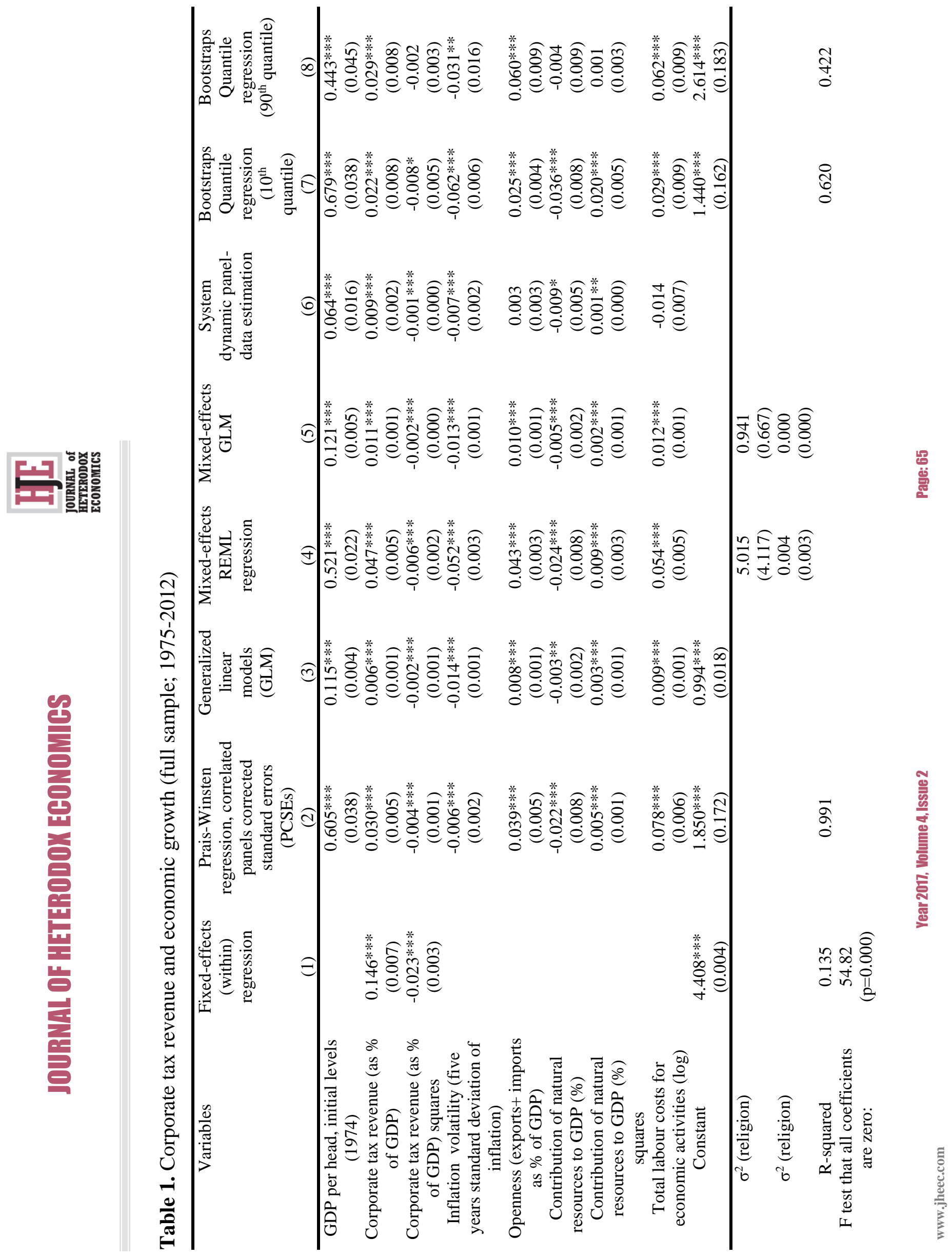




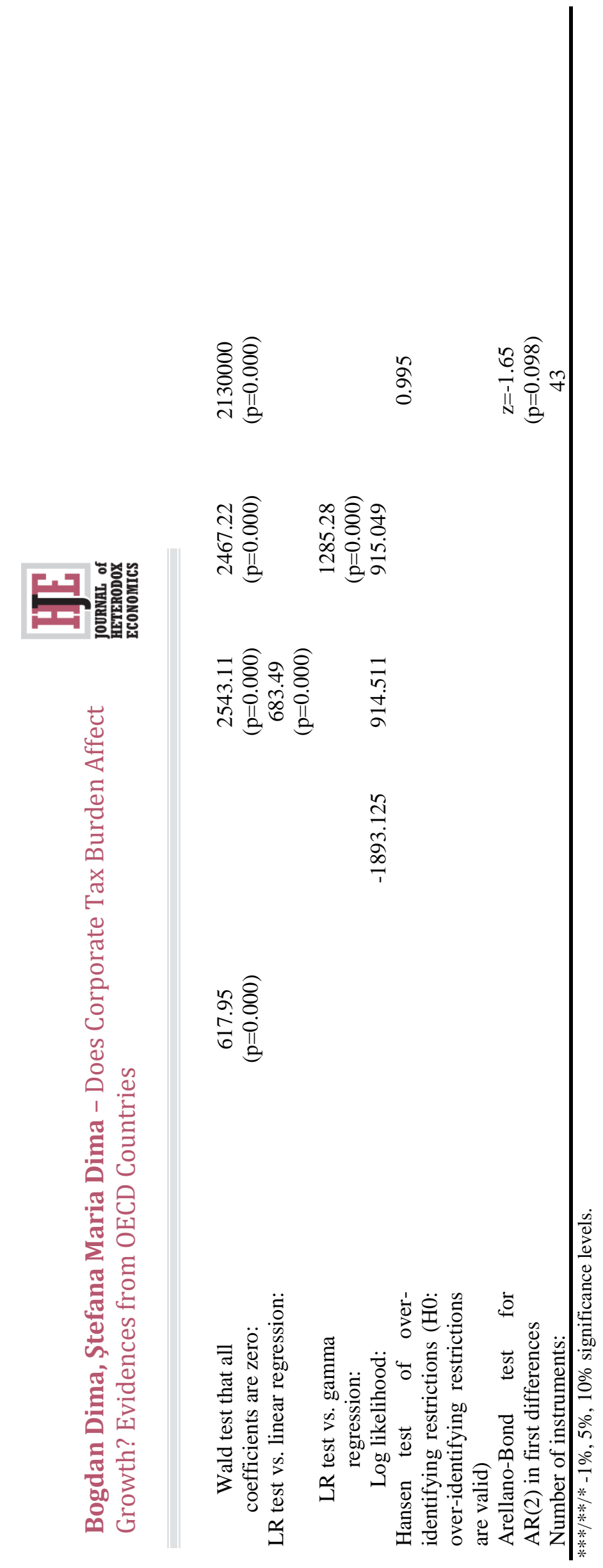

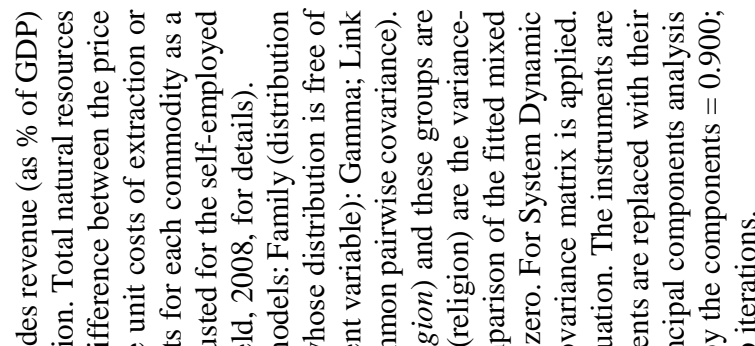

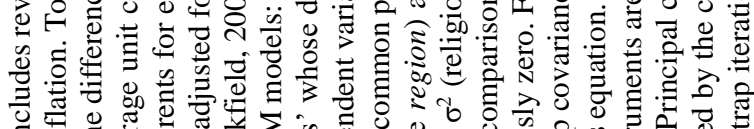

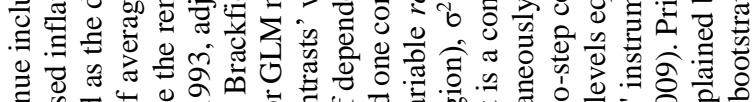

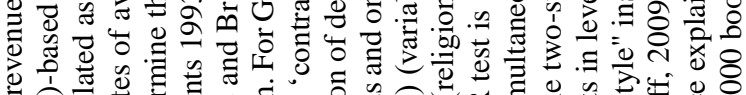

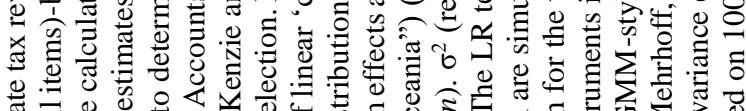

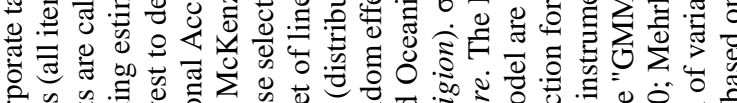

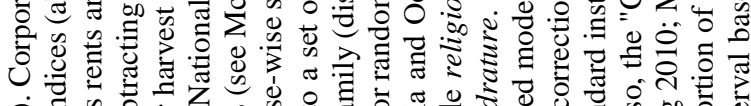

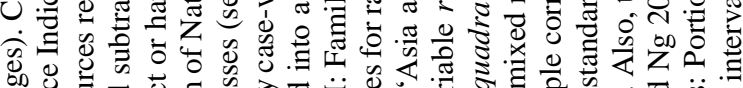

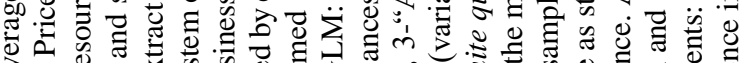

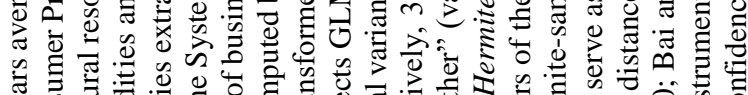

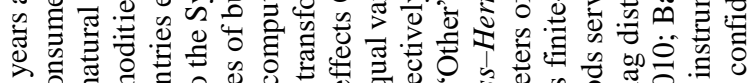

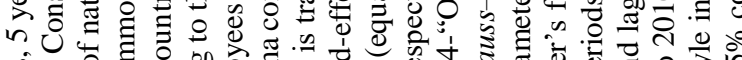
论

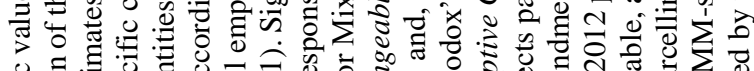

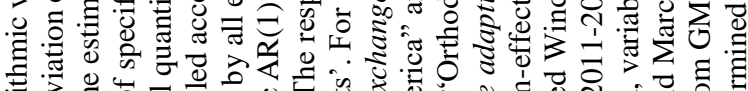

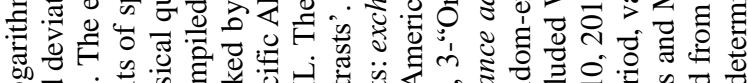

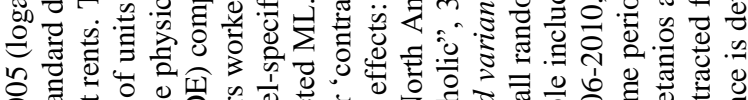

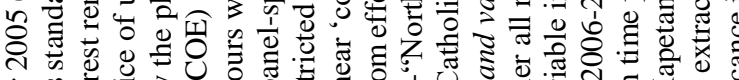

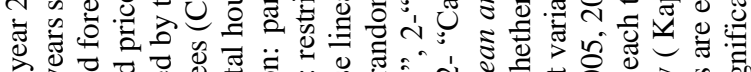

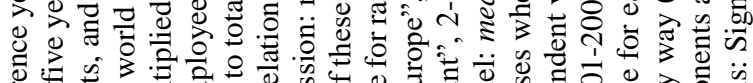

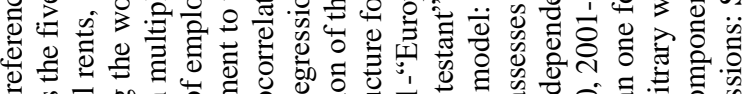

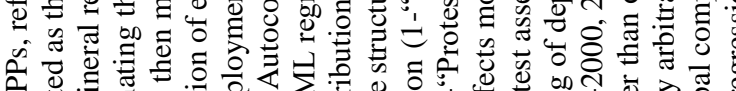

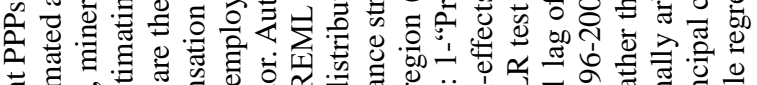

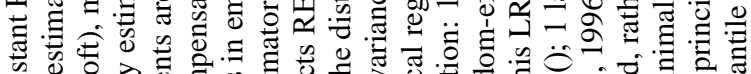

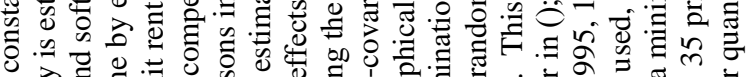

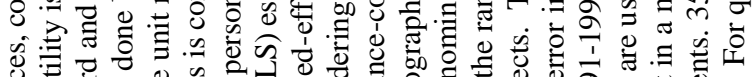

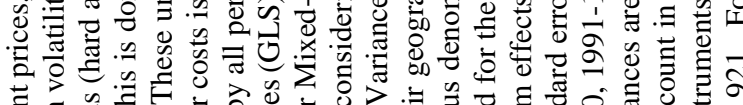

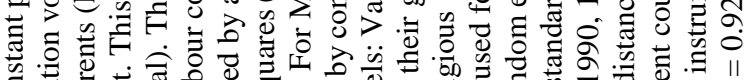

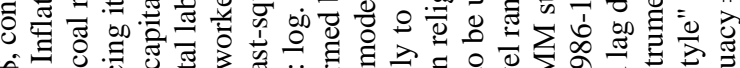
की

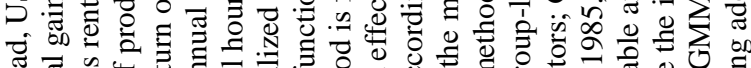

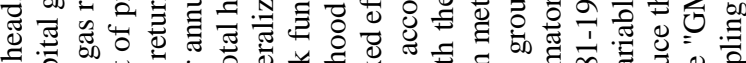

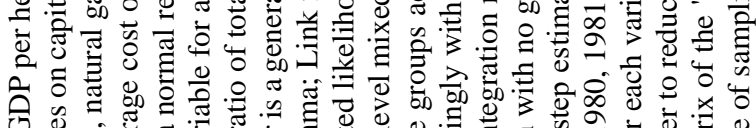

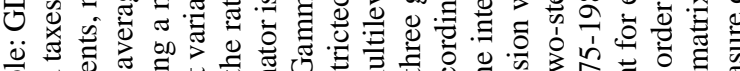

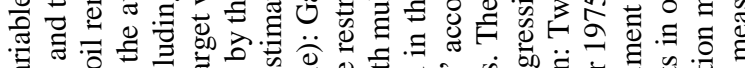

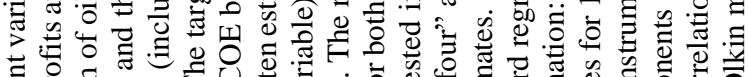

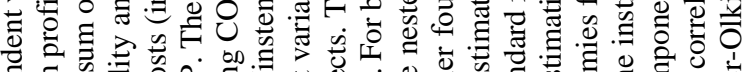

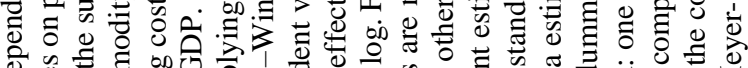

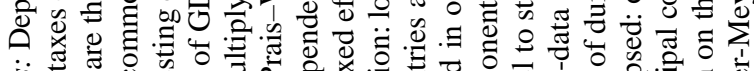

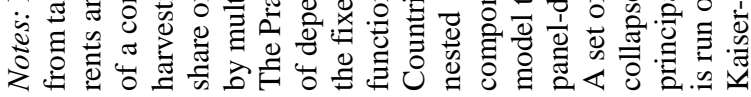


From the control variables, we do not find any evidences of a catching-up process in growth: the initial levels of GDP per capita exercise a positive (and statistically significant at $1 \%$ ) impact on subsequent growth. It should be noticed that this outcome involves growth levels and not necessarily growth rates. A country may improve its economic performances over time and growth rates among rich countries may converge as a consequence of globalization mechanisms. Still, the initial levels of economic activity matter for the current status of a country. Even if we are not addressing in greater details this issue, we argue that the evolutionary economic path is likely to be sensitive to the initial conditions. Among other factors, such non-catching-up result may be explained by the interactions between the design of fiscal policies and growth: different designs might lead to different outcomes in terms of economic performances, even if there are comparable endowments with resources, technology or human capital. Of course, the "all other being equal" hypothesis does not fully apply, not even for OECD countries, and a more complex explanation should be advanced.

Additionally, inflation volatility contributes to inhibiting growth for both estimates. However, the amplitude of this negative impact in the case of GLM estimators is twice that of Prais-Winsten estimators. Comparable to other findings in the literature, trade openness appears to stimulate growth, regardless of the used estimation method.

Interestingly enough, both estimation methods capture a $U$-shaped effect for the linkages between natural resources rents and growth, similar to Stijns (2005) findings.

Finally, it appears that, for OECD countries, the upward trend in the compensation of employees is accompanied by an increase in their skills and knowledge, with a positive impact on growth.

Overall, this initial analysis provides evidences for the existence of a non-linear influence of corporate taxation on growth, while the effects of the control variables are as expected.

\subsection{Mixed Effects Models}

We further consider the possibility to better describe the variance-covariance structures in the mixed effects framework. Column 4 of Table 1 reports the outcomes of linear mixedeffects models, while Column 5 reports the outcomes for multilevel mixed-effects generalized linear models.

In the estimation of the linear mixed-effects models, we involve the restricted maximum likelihood (REML) approach. This is a particular form of maximum likelihood estimation, using a likelihood function calculated from a transformed set of data. More exactly, it is based on the construction of a set of linear combinations of the response, which does not 
depend on the fixed effects, but solely on the variance components to be estimated. The distribution of such combinations is then used to form the likelihood. This approach accounts for the degrees of freedom lost by estimating the fixed effects. In addition, it provides a less biased estimation of random effects' variances (see Raudenbush and Bryk [2002]; Demidenko [2004]; McCulloch et al. [2008], for various aspects of mixed-effects models estimation).

Both estimators are revealing the same inverted $U$-shape effect of corporate tax statistically significant at 1\%. The amplitudes of level and squared terms are substantially smaller for mixed-effects GLM model. Still, for both methods, the net effect of corporate taxation on growth remains positive.

The (conservative) likelihood-ratio tests, comparing the three-levels linear model with the standard one-level linear model, and, respectively, the three-levels GLM model with the standard one-level GLM are both highly significant; suggesting that the fitted mixed models should be preferred to standard regression with no group-level random effects.

By using the dominant religious denomination and geographical region as nesting variables, we get more robust estimates and a more realistic description of causal inferences.

Similar to previous estimates, in the mixed effects framework, the net effect of corporate tax burden clearly dominates the effects induced by the control variables. This is followed, in respect to its relative explanatory capacity, by the evolution of labour costs and trade openness. The lowest relative importance in explaining growth corresponds to natural resources rents. All these variables remain statistically significant at $1 \%$.

\subsection{Reverse Causality Check}

As mentioned, the estimates might be affected by reverse causality issues. In order to check for it, we involve the instrumental GMM-System approach. The results are reported in Column 6 of Table 1.

The level and squared terms for corporate tax burden coefficients remain significant at $1 \%$ and comparable with previous estimates. By considering the reverse causality, the inverted $U$-shape effect is preserved. The net impact of corporate tax burden is still positive and the relative ratio between linear and non-linear terms is not substantially changed.

Interestingly, the initial level of growth is even more important than in other estimates and the non-catching-up result is more striking. From the other control variables, the inhibitory effect of inflation volatility is once again significant at $1 \%$. The trade openness lost its statistical significance (although its impact remains a positive one). The $U$-shaped 
effect of natural resources rents is maintained but its amplitude is substantially reduced. The same applies for the positive impact of total labour costs for economic activities.

The values of Hansen test that over-identifying restrictions are valid; the values of Arellano-Bond test for AR(2) in first differences support the quality of estimates.

\subsection{Quantile regressions}

An alternative approach for revealing the non-linear impact of tax burden may be represented by the quantile regressions approach. For this we consider the lower (10-th) and the upper (90-th) quantiles cases. The corresponding results are reported in Columns 7 and 8 of Table 1 . Several conclusions can be drawn.

First, it appears that, at the extremes of the income spectrum, the non-linear term loses its statistical significance. This term is significant only at $10 \%$ for the 10 -th quantile and completely loose significance at conventional levels for 90-th quantile. In the meantime, the linear term remains statistically significant at $1 \%$ with the shift from lower to higher quantiles, while there is no substantial difference in its corresponding amplitudes. One possible explanation might be that the non-linear impact of corporate tax burden is not necessarily stable across the growth path: as countries shift toward higher income levels, there are some structural adjustment processes that might contribute to higher adjustment flexibility and better capacity of absorbing the fiscal policy shocks.

Second, as expected, the initial level of growth is 1.5 times more important for lower income countries than for countries from upper quantiles of income.

Third, the inhibitory effect of inflation volatility, although it remains significant at $1 \%$, declines as importance at almost half from lower to higher quantiles.

Fourth, for the countries from the 90 -th quantile, there is virtually no significant effect on growth from the natural resources rents. Instead, the positive effect of total labour costs for economic activities appears to be almost three times larger than the one for lower quantile. Finally, the effect of trade openness is almost three-times larger for upper income countries. These countries are better able to benefit from international flows and to reap the paybacks of globalization processes.

Resuming, there is an inverted U-shape effect of corporate tax burden on growth, which is fair stable across various estimation methods. However, the non-linear term does not preserve its significance at the extremes of the income spectrum, reflecting the instability of the involved functional connexions across the growth trajectories.

From the control variables, the initial levels of growth, labour costs and trade openness are exerting the most substantial influences. In the next section, we evaluate the robustness of some of these findings. 


\section{Robustness assessment}

The 'Great Recession' of 2007-2010 can be reasonably viewed as a major source of regime-shift. In order to highlight its potential consequences, we re-apply our main estimators for the respective sub-period. The results are reported in Columns 1 to 4 of Table 2.

The most important result for this sub-period is that the impact of corporate tax burden becomes negative, during this period of economic downturn, while the statistic significance of the squared term is wiped out. The inhibitory impact of tax burden is more substantial for upper income quantiles. It might be argued that the capital markets in this sub-group of countries are highly integrated in international capital flows. Thus, it has been more likely for them to be effected by the consequences of the subprime crisis while, through various contamination mechanisms, these effects were translated into their real sectors (see, for instance, Crotty [2009] for an analysis of the structural flaws of the international financial systems and their contribution to the financial turmoil). For the lower income quantiles, the integration in international real flows (as captured as well by the degree of trade openness) appears to be a more powerful transmission channel.

When the instrumental GMM-System approach is considered, tax burden does not seem to influence growth any longer: there might be a change in the causality direction during this global instability period, running rather from economic conjuncture to the capacity of public authority to collect taxes. From the controls, only the initial levels of GDP per capita and trade openness remain statistically significant.

One of the most important transmission channels in our model is the capacity of public authorities to efficiently use the collected fiscal revenues as to provide public goods. However, such capacity is related to their functional efficiency, which is, inter alia, influenced by their relative size in the economy and society. Hence, we assess the robustness of our findings, by considering, as a supplementary control variable, the government size, as is this captured by government current expenditures for goods and services purchases (including compensation of employees). The results are displayed in Columns 5 to 7 of Table 2 . We notice a negative impact of government size on growth. Such impact is significant for the mixed-effects GLM estimates only at $5 \%$ and its relative amplitude is smaller compared to other controls. The government size virtually exercises no effects for lower income quantiles countries, but it is significant at $1 \%$ in the cases of higher income quantiles group. 


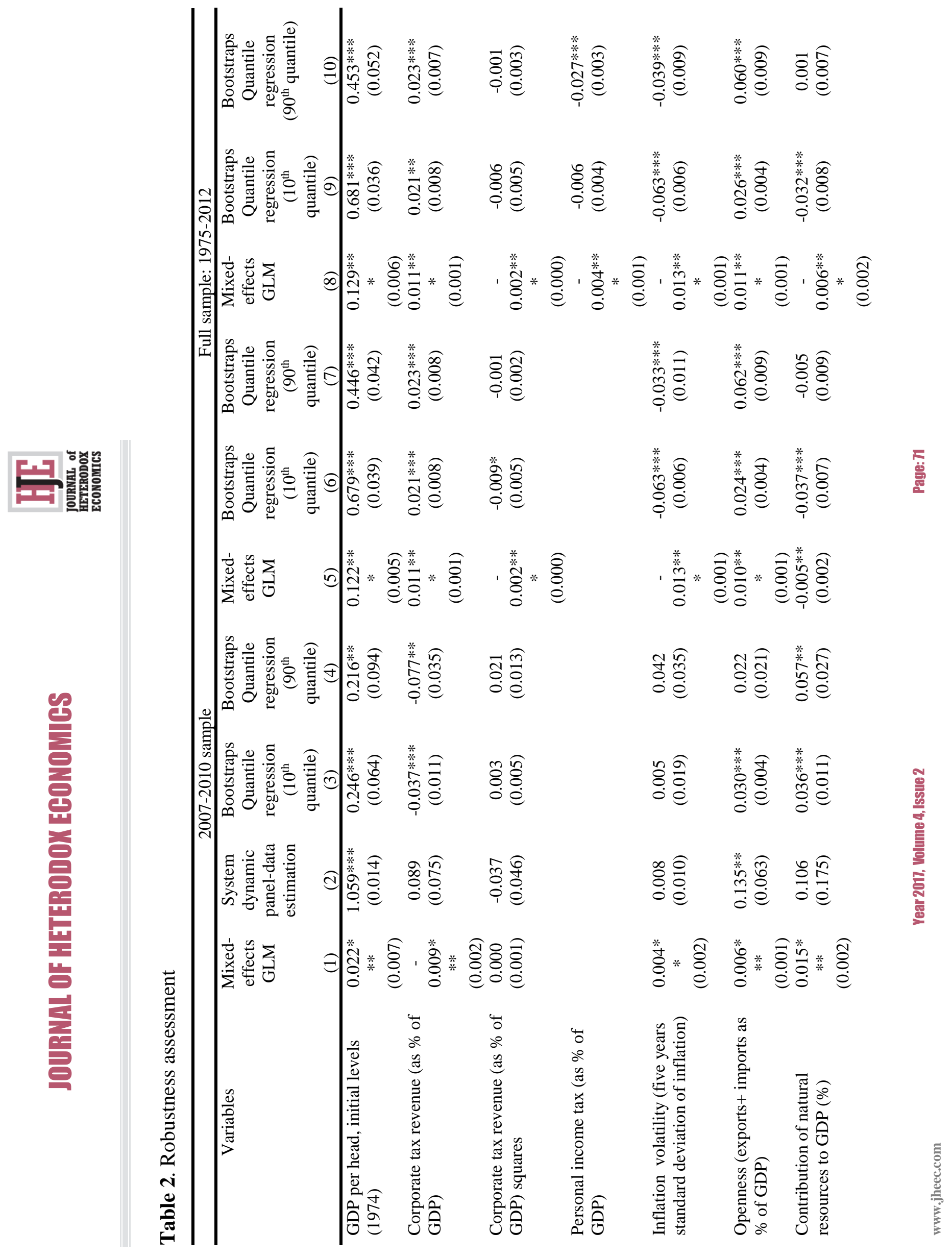




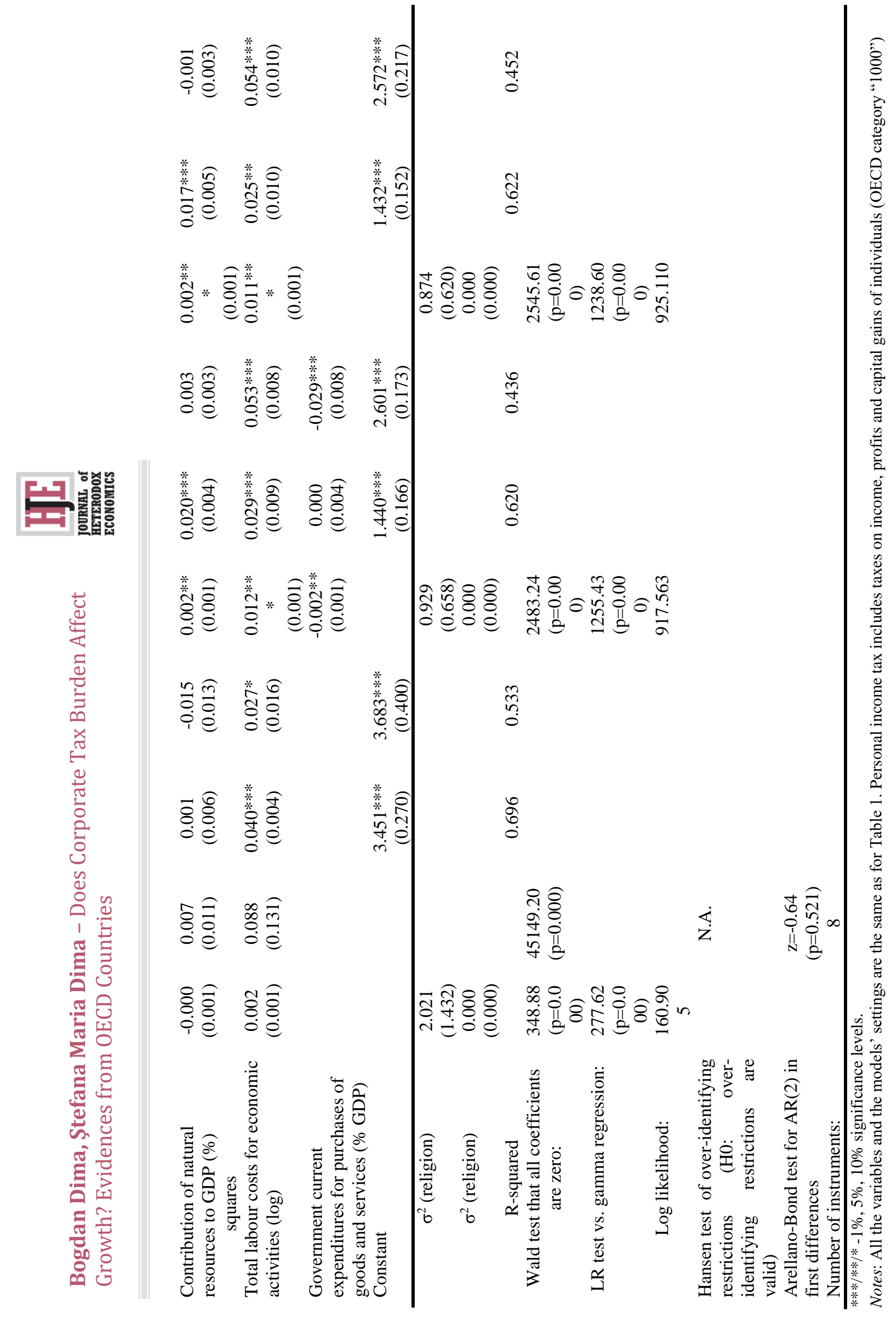

$\frac{\text { 종 }}{\text { 롤 }}$

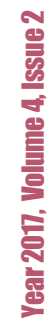


With the inclusion of this variable in the list of controls, the tax burden still exercises, in the framework of mixed-effects GLM, a significant impact at $1 \%$ on growth. There are no evidences of government size writing off the effects of corporate tax burden: the estimates are virtually the same as in the model not including this control. Of course, such result should be seen with caution. Nevertheless, it can provide an evidence (even if it is a limited one) supporting the idea of some distinctive effects of tax burden per se and, respectively, of the public resources allocation as in the proposed model.

For the other control variables, the inflation volatility, degree of openness and labour costs remain highly significant and exert similar types of effects. Meanwhile, the effects of natural resources rents are significant only at $5 \%$ and just for lower income quantiles countries.

Overall, the addition of government size as explanatory does not substantially modify the previous findings: the net effect of corporate tax burden remains comparable to the effects induced by other potential determinants of growth. This implies that the micro-level effects of corporate tax burden are only a part of the picture, while the macro-efficiency of public authorities in providing public goods is the other part, as these variables impact social utility.

Finally, relation (6) suggests that corporate tax burden and individual tax burden can differently impact growth as parameter $\omega_{t}^{1}$ may diverge from parameter $\omega_{t}^{2}$. Thus, we consider, as a potential alternative control, the personal income tax burden (as \% of GDP). The results are reported in Columns 8 to 10 of Table 2.

With the personal tax burden, the effects induced by corporate tax burden remain significant at $1 \%$, but are less substantial, the same as when it is not included in the list of explanatory variables. A part of corporate tax burden's impact on growth is overwritten by personal taxation. Still, the net impact of corporate taxes is, in the mixed-effects GLM estimates, around 2.5 times larger than the negative influence on growth lead by individuals' income component of taxes. In this framework, the relative importance of personal tax burden is lower in comparison not only with corporate taxation, but also with other controls.

We notice that the personal tax burden does not impact growth for lower income quantiles group. Yet, for the higher income quantiles group, the effects of personal taxation are alike those associated with corporate tax burden. The inflation volatility, degree of openness and labour costs influence growth similar to previous estimates. For the last of these variables, the corresponding effects seem lower. It can be argued that, since for the OECD countries wages and other components of labour cost display a certain degree of flexibility, what matters most, in terms of household consumption and savings' decisions, are the net wages and, thus, an increase in the personal taxation will affect growth, by means of these decisions. 
This assessment suggests that, for the entire time span, the inverted U-shaped impact of corporate tax burden on growth remains robust with the inclusion of some other control variables. However, the relationship between taxation and growth is significantly perturbed by periods of financial and real turmoil. This result implies that the involved transmission channels might actually be affected by growth phase related endogenous and exogenous shocks. For instance, in terms of our model, it can be argued that, during the economic downturn periods, there is a shift in the social preferences for the supply of public goods with a bigger role played by social expenditures and other 'safety net' type public mechanisms or by public expenditures with counter-cycle effects. Such shifts induce structural breaks in data, since they modify companies and households' behaviour, in terms of consumption, investment or savings, as well as their expectations in relation to future economic outlooks.

In addition, the increased economic uncertainty can modify the self-assessment of the individual income in respect to others, as well as of an individual's social standing. This type of effect can be boosted / inhibited by taxation and, especially, by its potential distortionary impact on distribution mechanisms. Finally, as our estimates suggest, for 2007-2010 crisis, the economic instability reduced the capacity of public authorities to efficiently collect the fiscal revenues.

\section{Conclusions}

The impact of tax burden on economic growth is an extensively debated topic. In this paper, we argue that some contributions in the literature might be the outcome of some neglected non-linearity in the relationship between taxation and growth. Hence, there can be a threshold, above which an increase in tax burden (an especially, in corporate taxation) might actually stimulate economic activity.

We advance an explanatory framework linking tax burden and economic output, via the social utility function of private agents. The main features of this framework are: a nonlinear shape of a potential Easterlin effect of growth on social satisfaction (with both absolute and relative income involved in the relationship between income and subjective well-being); the existence of several agents, for which the Ricardian Equivalence Theorem holds and, consequently, which are influenced in their decisions of future planned investments, consumptions and savings by the current changes in taxation; the direct impact of public expenditures, financed by fiscal revenues, on growth. In this framework, we argue that the impact of taxation on growth is modulated by the connections between social utility, the supply of public goods and services and policy preferences.

Based on annual panel data for a time span between 1975 and 2012 and for a sample of 21 OECD countries, we have tested for aggregate taxation-growth effects. Our main explanatory variable is not related to statutory and/or effective tax rates, but rather to tax 
burden, since this is able to reflect the efficiency of the fiscal mechanisms ensuring tax collection. Also, it can provide an estimate of the potential distortionary effects of taxation in respect to the economic scale.

While usually a negative taxation-growth connection is evidenced in the literature, we find a non-linear relation between corporate tax burden and economic growth. For OECD countries, the net effect is positive, although relatively small (but non-trivial over more than three decades). Overall, the inverted $U$-shape effect of corporate tax burden on growth remains robust, even if several control variables and estimation techniques are involved. Particularly, the results improve if countries are nested into a region and regions are nested into a religious denomination group. Still, the non-linear term does not preserve its significance at the extremes of the income quantiles, as the involved transmission channels are not stable along various growth trajectories. Also, for the financial and real turmoil period of 2007-2010, the transmission channels are perturbed by the various shocks and the tax burden-growth relation becomes a negative one, without a significant non-linear component.

From the controls, inflation volatility, trade openness and labour costs appear to exercise significant effects on growth, while there are less robust evidences for a $U$-shaped effect of natural resources rents. Another interesting result is that, if growth is described in terms of GDP per head, than there are no evidences of a non-catching-up process.

Although we focus on the impact exercised on growth by the corporate tax burden, the proposed approach can be extended to the other components of tax system, as well.

What are the main policy implications of our findings? In any case, several such implications can be highlighted. First, it seems that, in order not to harm growth, an increase in corporate tax burden should be accompanied by an increase in the amount and efficiency of growth-oriented public goods. Second, there might be a saturation point up to it is possible to increase taxation without affecting growth. After such point, one can expect the detrimental effects of tax burden to prevail. Third, it can be expected the taxation-growth relation to vary according to the global development stages. Hence, caution should be exercised in making 'one fits all' type policy recommendations.

\section{References}

Acosta-Ormaechea, S., \& Yoo, J. (2012) Tax Composition and Growth: A Broad Cross-Country Perspective. IMF Working Paper WP/12/257, Available at: https://www.imf.org/ external/pubs/ft/ wp/2012/wp12257.pdf.

Andrews, M.J., Schank, T. \& Upward. R. (2006) Practical fixed-effects estimation methods for the three-way error-components model. Stata Journal, 6: 461-481. 
Andersen, L., \& Babula, R. (2008) The Link Between Openness and Long-Run Economic Growth. United States International Trade Commission Journal of International Commerce and Economics, July: 1-20, Available at: http://www.usitc.gov/publications/332/journals/ openness_growth_link.pdf

Andrikopoulos, A., Loizides, I., \& Prodromidis, K. (2004) Fiscal policy and political business cycles in the EU. European Journal of Political Economy, 20(1):125-152.

Arellano, M., \& Bond, S. (1991) Some tests of specification for panel data: Monte Carlo evidence and an application to employment equations. The Review of Economic Studies, 58: 277-297.

Arellano, M. \& Bond, S. (1998) Dynamic Panel data estimation using DPD98 for Gauss: A guide for users.

Arellano, M. \& Bover, O. (1995) Another look at the instrumental variable estimation of errorcomponents models. Journal of Econometrics 68: 29-51.

Arnold, J. (2008) Do tax structures affect aggregate economic growth? Empirical evidence from a panel of OECD countries. OECD Working Paper, 643, Available at: http://www. oecdilibrary.org/economics/do-tax-structures-affect-aggregate-economic-growth_236001 777843 ? crawler $=$ true.

Arnold, J., Brys, B., Heady, C., Johansson, A., Schwellnus, C., \& Vartia, L. (2011). Tax policy for economic recovery and growth. The Economic Journal, 121, February: F59-F80.

Auerbach, A.J. (2005) Taxation and Capital Spending. Paper presented at Academic Consultants Meeting of the Board of Governors of the Federal Reserve System, October 7, Available at: http://eml.berkeley.edu/ auerbach/capitalspending.pdf.

Bai, J., \& Ng, S. (2010) Instrumental Variables Estimation in a Data Rich Environment. Econometric Theory, 26(6): 1577-1606.

Barro, R. (1990) Government spending in a simple model of endogenous growth. Journal of Political Economy, 98(5), Part.2:s103-s125.

Barro, R.J., \&McCleary, R.M. (2003) Religion and economic growth across countries. American Sociological Review, 68(5):760-781.

Barro, R.J., \& Redlick, C.J. (2011) Macroeconomic effects from government purchases and taxes. Quarterly Journal of Economics, 126: 51-102.

Bassett, G., \& Koenker, R. (1978) Asymptotic Theory of Least Absolute Error Regression. Journal of American Statistical Association, 73: 618-622.

Becketti, S. (2013) Introduction to Time Series Using Stata. College Station, TX: Stata Press.

Bergh, A., \& Henrekson, M. (2011) Government Size and Growth: A Survey and Interpretation of the Evidence. Journal of Economic Surveys, 25(5), December: 872-897.

Bleaney, M., Gemmell, N., \& Kneller, R. (2001) Testing the endogenous growth model: Public expenditure, taxation and growth over the long run. Canadian Journal of Economics, 34: 36-57.

Blundell, R., \& Bond, S. (1998) Initial conditions and moment restrictions in dynamic panel data models. Journal of Econometrics 87: 115-143.

Capolupo, R. (2000) Output Taxation, Human Capital and Growth. The Manchester School, 68(2):166-183. 
Corcoran, K., Crusius, J., \& Mussweiler, T. (2011) Social comparison: Motives, standards, and mechanisms. In D. Chadee (Ed.), Theories in social psychology (pp. 119-139). Oxford, UK: Wiley-Blackwell.

Crotty, J. (2009) Structural causes of the global financial crisis: a critical assessment of the "new financial architecture'. Cambridge Journal of Economics, 33: 563-580.

Dackehag, M. \& Hansson, A. (2012) Taxation of income and economic growth: an empirical analysis of 25 rich OECD countries. Working Paper, 6, Department of Economics, Lund University, March, Available at: http://project.nek.lu.se/publications/ workpap/papers/WP12_6.pdf.

Demidenko, E. (2004) Mixed Models: Theory and Applications. Hoboken, NJ: Wiley.

Easterlin, R.A. (1974) Does Economic Growth Improve the Human Lot? Some Empirical Evidence, In P. A. David and M. W. Reder (Eds.), Nations and Households in Economic Growth: Essays in Honour of Moses Abramovitz, New Yok and London: Academic Press.

Easterlin, R.A. (1995) Will Raising the Incomes of All Increase the Happiness of All. Journal of Economic Behavior and Organization, 27:1, 35-47.

Easterlin, R.A., McVey, L.A., Switek, M., Sawangfa, O., \& Smith, J.S. (2010) The happinessincome paradox revisited. PNAS, 107(52): 22463-22468.

Freund, C., \& Bolaky, B. (2008) Trade, regulations, and income. Journal of Development Economics, 87(2), October: 309-321.

Gemmell, N., Kneller, R., \& Sanz, I. (2013) The Growth Effects of Tax Rates in the OECD. Victoria University of Wellington - Victoria Business School Working Papers in Public Finance, Working Paper, 2, Available at: http://www.victoria.ac.nz/sacl/about/cpf/publica tions/pdfs/WP02_2013_TaxRatesinOECD_22032013.pdf.

Gordon, R.H., \& Lee, Y. (2005) Tax structure and economic growth. Journal of Public Economics, 89(5-6): 1027-1043.

Hardin, J.W., \& Hilbe, J.M. (2012) Generalized Linear Models and Extensions, 3rd edition. College Station, TX: Stata Press.

Irmen, A., \& Kuehnel, J. (2008) Productive Government Expenditure and Economic Growth. University of Heidelberg, Department of Economics, Discussion Paper Series, 464 (May).

Judson, R., \& Orphanides, A. (1999) Inflation, Volatility and Growth. International Finance, 2(1), April: 117-138.

Kapetanios, G., \& Marcellino, M. (2010) Factor-GMM estimation with large sets of possibly weak instruments. Computational Statistics \& Data Analysis 54(11): 2655-75.

Koenker, R., \& Bassett, G., Jr. (1978) Regression Quantiles. Econometrica, 46(1): 33-50.

Knack, S. (Ed.) (2003) Democracy, Governance and Growth. Ann Arbor: The University of Michigan Press.

Knight, K. (2008) Asymptotics of the regression quantile basic solution under misspecification. Applications of Mathematics, 53(3): 223-234.

Lo, A.W. (2012) Reading about the Financial Crisis: A Twenty-One-Book Review. Journal of Economic Literature, 50(1): 151-178. 
McCleary, R.M., \& Barro, R.J. (2006) Religion and Political Economy in an International Panel. Journal for Scientific Study of Religion, 45(2), June: 149-175.

McCulloch, C.E., Searle, S.R. \& Neuhaus, J.M. (2008) Generalized, Linear, and Mixed Models, 2nd edition. Hoboken, NJ: Wiley.

Mehrhoff, J. (2009) A solution to the problem of too many instruments in dynamic panel data GMM. Discussion Paper Series, 1(31).

McKenzie, R. \& Brackfield, D. (2008) The OECD System of Unit Labour Cost and Related Indicators. OECD Statistics Working Papers 2008/04, OECD Publishing. Available at: http://dx.doi.org/10.1787/243142116028.

Mendoza, E., Milesi-Ferretti, G.M., \& Asea, P. (1997) On the ineffectiveness of tax policy in altering long-run growth: Harberger's superneutrality hypothesis. Journal of Public Economics, 66: 99-126.

Milesi-Ferretti, G.M., \& Roubini, N. (1998a) On the taxation of human and physical capital in models of endogenous growth. Journal of Public Economics, 70: 237-254.

Milesi-Ferretti, G.M, \& Roubini, N. (1998b) Growth Effects of Income and Consumption Taxes. Journal of Money, Credit and Banking, 30(4):721-744.

Ng, E.S.-W., Carpenter, J. R., Goldstein, H. \& Rasbash, J. (2006) Estimation in generalised linear mixed models with binary outcomes by simulated maximum likelihood. Statistical Modelling, 6: 23-42.

Nordhaus, W. (1989) Alternative approaches to the political business cycle. Brookings Papers in Economic Activity, (2):1-49.

OECD (2012) Education at a Glance 2012: OECD Indicators, OECD Publishing, Available at: http://dx.doi.org/10.1787/eag-2012-en.

Portnoy, S. (1991) Asymptotic behavior of regression quantiles in non-stationary, dependent cases. Journal of Multivariate Analysis, 38(1): 100-113.

Rabe-Hesketh, S., \& Skrondal, A. (2006) Multilevel modelling of complex survey data. Journal of the Royal Statistical Society, Series A, 169: 805-827.

Rabe-Hesketh, S., \& Skrondal, A. (2012) Multilevel and Longitudinal Modeling Using Stata, 3rd edition. College Station, TX: Stata Press.

Rauch, J., \& Evans, P. (2000) Bureaucratic Structure and Economic Performance. Journal of Public Economics, 74: 49-71.

Raudenbush, S.W., \& Bryk, A.S. (2002) Hierarchical Linear Models: Applications and Data Analysis Methods, 2nd edition. Thousand Oaks, CA: Sage.

Roodman, D. (2009a) How to Do xtabond2: An Introduction to "Difference" and "System" GMM in Stata. Stata Journal, 9(1): 86-136.

Roodman, D. (2009b) A Note on the Theme of Too Many Instruments. Oxford Bulletin of Economics and Statistics, 71(1), February: 135-158.

Sacks, D.V., Stevenson, B., \& Wolfers, J. (2012) The new stylized facts about income and subjective well-being. Emotion, NCBI Resources (December), 12(6): 1181-1187.

Schunck, R. (2013) Within and between estimates in random-effects models: Advantages and drawbacks of correlated random effects and hybrid models. Stata Journal, 13: 65-76. 
Schuknecht, L. (1996) Political Business Cycles and Fiscal Policies in Developing Countries. Kyklos, 49(2), May: 155-170.

Swank, D. (2002) Global Capital, Political Institutions, and Policy Change in Developed Welfare States. Cambridge: Cambridge University Press.

Stijns, J.-F.C. (2005) Natural resource abundance and economic growth revisited. Resources Policy, 30(2), June: 107-130.

Uhlig, H., \& Yanagawa, N (1996) Increasing the Capital Income Tax may lead to Faster Growth. European Economic Review, 40, November: 1521-1540.

Veenhoven, R., \& Vergunst, F. (2013) The Easterlin illusion: economic growth does go with greater happiness. Paper presented at the 11th conference of the International Society for Quality Of Life Studies (ISQOLS), November 1-4, 2012, Venice, Italy / MPRA Paper No. 43983, Available at: http://mpra.ub.uni-muenchen.de/43983/ 1/MPRA_paper_43983.pdf.

Weiss, A.A. (1990) Least Absolute Error Estimation in the Presence of Serial Correlation. Journal of Econometrics, 44: 127-158.

Windmeijer, F. (2005) A finite sample correction for the variance of linear efficient two-step GMM estimators. Journal of Econometrics, 126: 25-51.

Xing, J. (2011) Does tax structure affect economic growth? Empirical evidence from OECD countries. Oxford University Center for Business Taxation Working Papers WP11/20, Available

at: http://www.sbs.ox.ac.uk/sites/default/files/Business_Taxation/Docs/Publicati ons/Working_Papers/Series_11/WP1120.pdf.

Yanikkaya, H. (2003) Trade openness and economic growth: a cross-country empirical investigation. Journal of Development Economics, 72: 57-89. 
Bogdan Dima, Ştefana Maria Dima - Does Corporate Tax Burden Affect Growth? Evidences from OECD Countries 